\title{
Empirical Analysis on the Factors Affecting the Development of Green Economy in Guizhou Province, China
}

\author{
Chenggang Li, Yandan Xue, Lingyun Luo, Xiaoliang Liu, Mingguo Zhang and \\ Wulin Zhang
}

\author{
Faculty of Finance, Guizhou University of Finance and Economics, Guiyang, China
}

Keywords: Green economy; Multivariate linear regression model; Per capita energy; Industrial wastewater emissions; Utilization of industrial solid waste

\begin{abstract}
In this paper, multiple linear regression models were used to analyze the factors of affecting Green economic development in Guizhou Province, China and to identify the weight of all the factors. Indicator of Green economic growth is the per capita GDP of Guizhou Province. The arguments are per capita energy, industrial wastewater emissions and industrial solid waste utilization. This paper uses these factors to establish multiple linear regression models, uses E-views software to analyze these three elements, and draws the relationship and affection of the factors on the development of the green economy. Per capita energy and utilization rate of industrial solid waste have a significant positive effect on the green economic growth in Guizhou Province. Industrial waste water emissions have a negative effect on green economic growth. Finally, this essay provides a theoretical basis and reference recommendations to the green economic growth in Guizhou province.
\end{abstract}

\section{Introduction}

With the rapid development of Chinese economy, China's industry has rapid development. Made in China has provided the necessary commodities for the people from country to the world. As result, the human society has been rapid development. But with industrial development, environmental issues become increasingly prominent. The discharge of industrial waste water causes serious pollution of the city's groundwater. Industrial emissions, vehicle exhaust and other factors cause the common excessive of the concentration of suspended particles in the air, fog and haze frequently. Our current problem of environmental pollution is serious. Industrial transformation and upgrading are imminent. The original high energy consumption and high pollution enterprises should convert to low energy consumption and low pollution direction, toward sustainable development and transformation. For Guizhou Province, it has a good ecological environment. The development of economy must take the road of green development. Therefore, the study of factors influencing the development of the green economy has great significance for the development of green economy in Guizhou Province.

\section{Literature Review}

Many scholars conduct in-depth researches in green economic development. Hallegatte et al. (2011) think that the green economy has made a full and cleaner use of resources in the process of economic growth. Through the development of appropriate environmental policies, green policies contribute to economic growth. Wang (2011) puts forward the green theoretical analysis of economic growth, and points out the key parameters to control the green economy. Zhao et al. (2011) use the example of California to introduce the experience of establishing green economic development measure system, and provide a scientific basis to develop green economy. Following the development of green economy measure system establishment principle, Xue (2012) establishes green economic development evaluation system, and empirically measures Jinan's green economic development during the 11th Five Year Plan. Liu (2013) analyzes the green economy indices and development strategy. He gets the green economy development index - energy consumption per unit of GDP, per capita waste water et, and proves that the level of development of green economy is 
improved year after year. Xiang and Zheng (2013) point out that China's green economy development index is a comprehensive reflection of the process of production and consumption to save energy reduce waste and provide green products and services, prompting the relative number of trends and changes in levels of health coordinated development of ecology. Using the SBM model, Qian and Liu (2013) calculate China's provinces green economy efficiency value, and obtain the inverted U-shaped relationship between green economic efficiency and per capita GDP. Through spatial statistical analysis, in the view of the relationship among the economic indicators of green economy level, social indicators, environmental and resources indicators and the policy index, Dan (2014) researches the status of green economic development level. By analyzing the China's economic development and industrial structure, Peng and Sun (2015) point out the economic restructuring pressures and challenges, and point out that the way of China's development is the cultivation and development of green industries, the establishment of the mandatory upgrade mechanism of traditional industries, encouraging the development of mechanisms for new green industry and TFP economic development evaluation system, and the establishment of green consumption pattern of the whole society. In the background of natural resources and environmental capacity control of world economic and social development bottleneck effect, Zheng (2015) apply the literature analysis method to summarize the connotation and extension of green economy, green development strategies and policies, drive or constraints factors, green transformation theory method and practical application.

The above studies show that the development of green economy and green economy transition is the development model of the traditional economic transformation. These scholars have also studied the key parameters and influencing factors in the development of green economy. Taking Guizhou Province as an example, this paper uses multiple linear regression model to analyze the factors affecting the development of green economy.

\section{Variable Selection and Model Construction}

In this paper, the economic growth indicator is per capita GDP of Guizhou province. Resource saving indicator is the per capita energy in Guizhou Province. Environmental indicators are industrial wastewater emissions, industrial solid waste utilization rate. The per capita GDP in Guizhou province were selected as the dependent variable, select the resource conservation and environmental protection index as independent variables to establish the linear regression model. This paper sets the regression model of time-series data as follows:

$$
Y_{t}=\beta_{0}+\beta_{1} X_{1 t}+\beta_{2} X_{2 t}+\beta_{3} X_{3 t}+\mu_{t}
$$

In the formula, Yt is Guizhou's per capita GDP in the year of t. X1 is per capita energy in Guizhou province. X2 is industrial waste water emissions. X3 is the utilization of industrial solid waste.

The empirical data used in this paper is from 1990 to 2013. These data come from the statistics of National Bureau, China city statistical yearbook of Guizhou Province, and Guizhou Province Bureau of statistics yearbook.

\section{Empirical Analyses}

Descriptive Statistics. Descriptive statistical analysis of per capita GDP, per capita energy of Guizhou Province, industrial waste water discharge and the industrial solid waste utilization rate: the average per capita GDP is 6098.5 , the median is 3128.5 , the maximum is 23151 , the minimum is 810 , the standard deviation is 6298.154 , the deviation is 1.433 , and the peak value is 3.9812 . The mean of independent variables respectively is $1408.283,2.2036,0.341$, median respectively is 68.2 , $2.29,0.303$, maximum respectively is $2835.25,3.55,0.617$, minimum respectively is $652.79,1.17$, 0.126 , standard deviation respectively is $627.5652,0.7229$ and 0.1296 , deviation respectively is $0.81,-0.0067,0.4286$ and peak value respectively is $2.66,1.758,2.523$.

Correlation Analysis. To analyze the correlation among variables, we can find that the per 
capita energy and industrial waste water emissions in Guizhou province is a negative correlation, and industrial solid waste utilization is positive correlation. Industrial wastewater emissions and industrial solid waste utilization rate is negatively correlated.

Empirical Analysis. The parameters of the model were estimated by E-views software. The initial estimation results are shown in Table 1.

Table 1 Initial estimation results

\begin{tabular}{|l|l|l|l|l|}
\hline Variable & Coefficient & Std.error & t-statistic & Prob \\
\hline X1 & 8.530915 & 0.816149 & 10.45265 & 0.0000 \\
\hline X2 & 773.2931 & 432.8668 & 1.786446 & 0.0919 \\
\hline X3 & -3521.202 & 2240.651 & -1.571509 & 0.1345 \\
\hline C & -7309.118 & 1711.098 & -4.271594 & 0.0005 \\
\hline F-statistic & 116.9979 & \multicolumn{2}{|l|}{ Durbin-Watson stat } & 1.095266 \\
\hline
\end{tabular}

By checking the table, $t_{0.10}(20)=1.325$. All variables pass through t test. The statistics is significant. And $\mathrm{f}(3,20)=2.38$, and $\mathrm{F}$ test is too large. There must be multi-co linearity between variables. Meanwhile, the t statistic can pass the test, but the DW is 1.095265.According to the results of table 1 , there is a correlation.

Because DW=2 (1-p), $p=0.4524$, we can use the generalized difference method to estimate the model again. Using the Cochrane-Orcutt method to estimate the model, regression results: Durbin-Watson stat is 1.888114 , du $<\mathrm{DW}<4, \mathrm{Du}-\mathrm{DW}=1.888114$, which indicates that there is no self-correlation in the model.

The different variances test of the estimated results, R-squared is 0.1812376. Because $\mathrm{n} * \mathrm{R}^{2} \square \chi^{2}(m), n^{*} R^{2}=0.78832$, Number of constraints $\mathrm{m}=9$, the free degree of 9 and $5 \%$ square critical value is 16.919 , there is no heteroskedasticity. Moreover, X1 and X2 X3 are all positive, which is in line with economic significance. The final regression equation is:

$$
\begin{gathered}
Y=-3930.673+6.926204 X_{1}-601.9068 X_{2}+720.9701 X_{3} \\
(-2.051387)(6.916190) \quad(-1.081100) \quad(1946.344)
\end{gathered}
$$

The following conclusions can be drawn from the model estimation results:

(1) From the model, it is found that per capita energy, industrial waste water discharge and industrial solid waste utilization in Guizhou province have a significant impact on the per capita GDP in Guizhou province.

(2) Per capita energy and industrial solid waste have a positive impact on the per capita GDP. Per capita energy consumption increases by 1 unit, and the per capita GDP increases by 6.92 units. The utilization rate of industrial waste water increases by 1 unit, the per capita GDP increases by 720.9 units. Therefore, the per capita GDP can be improved by increasing the utilization of per capita energy and industrial waste water, thereby promoting the development of green economy in Guizhou province.

(3) The industrial waste water discharge has a negative impact on the per capita GDP. The industrial wastewater emissions increase by 1 unit, the per capita GDP will be reduced by 601.9 units. Therefore, the per capita GDP of Guizhou province can be improved by reducing the discharge of industrial waste water, which can promote the development of green economy in Guizhou province.

\section{Conclusions and Policy Recommendations}

This paper selects the per capita GDP of Guizhou Province as dependent variable, and selects the resource saving indicators and environmental indicators as independent variables to establish the linear regression model. This paper empirically analyzes the influencing factors of green economy of Guizhou Province and their influence size on green economy. Empirical results show that: per capita energy, industrial wastewater discharge amount and industrial solid waste utilization in 
Guizhou Province have a significant impact on the per capita GDP. Per capita energy and industrial solid waste of Guizhou Province have positive effect on the per capita GDP. Industrial wastewater discharge has a negative effect on the per capita GDP in Guizhou Province.

According to the results of this paper, the following policy recommendations are put forward:

(1) Guizhou Province must develop the green economy. The enterprises should reduce the discharge of industrial waste water, improve the utilization rate of industrial solid waste, and improve energy efficiency. The government should formulate the corresponding environmental policy and the green economic policy to provide the good environment and the policy support for the green economy development.

(2) Provide green credit support, financing and rational allocation of resources, efficient allocation of resources. Provide financial support and technical support to the environment-friendly enterprises, and increase loan conditions of the high energy consumption and high pollution enterprises. The credit policy for the high pollution industry limits on loans. Environmental protection industry and technological innovation industry give preferential interest rates.

(3) Establish the mechanism of capital oriented. For the reallocation of capital stock, make use of funds to meet the needs of economic development, adapt to the laws of the economy, adjust the quantitative relationship of capital among the industries, and complete industrial structure adjustment in the foundation of expanding the production scale.

\section{References}

[1] S. Hallegatte, G. Heal and M. Fay: From Growth to Green Growth-A Framework [J]. NBER Working Paper No. 17841, 2011.

[2] H. Wang: The Analysis of Economic Growth based on Green Economic Growth Model [J]. Energy Procedia, 2011, Vol.11: 4867-4872.

[3] Y. Zhao: The experience and reference of establishing a measure system of green economic development from developed countries [J]. Economic Review, 2011, (1): 34.

[4] L. Xue: Construct the measurement system of green economic development [J]. Statistics and Decision, 2012, (18): 21.

[5] X. Liu: Measurement indicators and development countermeasures for the green economy [J]. Macroeconomic Management, 2013, (2): 39-40.

[6] S. Xiang, R. Zheng: Study on the green economic development index in China [J]. Statistical Research, 2013, 5 (3): 72-79.

[7] Z. Qian: Regional differences in China's green economy and their determinants [J]. China Population, Resources and Environment, 2013, 6(7): 104-109.

[8] D. Yao: The construction of China's green economic index system and the spatial statistical analysis [D]. Guangzhou: Jinan University, 2014, 20-50.

[9] S. Peng, X. Sun: Research on challenges and strategies for China's green economy development [J]. Chinese Journal of Population Resources and Environment, 2015, Vol.13 (2), pp. 127-131.

[10]D. Zheng: The research summary of green economy, green development and green transformation [J]. Ecological Economy, 2015, 31(2): 64-68. 